\title{
PREDIKSI TINGKAT KESUKSESAN PROMOSI BANK DENGAN ALGORITMA DNN
}

\author{
Oscar $^{1}$, Nurlaelatul Maulidah ${ }^{2}$, Annida Purnamawati ${ }^{3}$, Destiana Putri ${ }^{4}$, Hilman F. Pardede \\ ${ }^{12345}$ Sekolah Pascasarjana Ilmu Komputer, STMIK Nusa Mandiri, Jakarta, Indonesia \\ ${ }^{5}$ Pusat Penelitian Informatika, Lembaga Ilmu Pengetahuan Indonesia, Indonesia \\ e-mail : 14002331@nusamandiri.ac.id, 14002433@nusamandiri.ac.id, \\ 14002403@nusamandiri.ac.id, 14002366@ nusamandiri.ac.id, hilman@nusamandiri.ac.id
}

\begin{abstract}
Telemarketing is one effective way for promoting products. However, it is often difficult to measure the success of telemarketing. Therefore, a way to predict the success rate of telemarketing, and hence strategies could be planned to increase the success rate. In this study, we evaluate several implementations of machine learning for prediction the success of telemarketing. The evaluated methods are Deep Neural Network (DNN), Random Forest, and $K$-nearest neighbor $(K-N N)$. We validate our experiments using 10 fold cross validation and our experiments show that DNN with 3 hidden layers outperforms other methods. Accuracy of $90 \%$ is achieved with the DNN. It is better than Random Forest and KNN that achieve accuracies of algorithm and $88 \%$ and $89 \%$.
\end{abstract}

Keywords-Bank Marketing, DNN, KNN, Random Forest.

\begin{abstract}
ABSTRAK
Telemarketing adalah promosi yang efektif dalam mempromosikan produk. Strategi pemasaran ini dilakukan bank dengan menawarkan produk kepada nasabah, salah satu produk yang ditawarkan bank adalah deposito. Sulitnya mengetahui keputusan klien Telemarketing untuk menempatkan deposito di bank menyebabkan bank selalu menghadapi ancaman krisis keuangan. Dalam mendukung telemarketing untuk meningkatkan tingkat keberhasilan, keputusan klien untuk memprediksi keberhasilan dibuat. Dalam penelitian ini dilakukan percobaan dan pengujian dengan beberapa metode yaitu Klasifikasi yang meliputi Deep Neural Network (DNN), Random Forest, K-nearest neighbour (K-nn). Dengan menambahkan teknik data mining berupa Cross Validation yang bertujuan untuk mendapatkan hasil akurasi yang maksimal. Metode ini sering disebut dengan $\mathrm{k}$-fold cross validation, dimana percobaan $\mathrm{k}$ kali untuk satu model dengan parameter yang sama dan menggunakan aplikasi Multi Layer Percepton (MLP) hasil investigasi dalam pengujian prediksi tingkat keberhasilan promosi bank menggunakan 20: 80 data pengujian dan data pelatihan. Dengan menggunakan arsitektur yang baik berdasarkan hasil pengujian yaitu 3 hidden layer, learning rate dan 10 epoch testing experiment diperoleh nilai akurasi terbaik 90\% dengan metode DNN dan akurasi $89 \%$ dengan algoritma KNN dan $88 \%$ dengan algoritma Random Forest.
\end{abstract}

Kata Kunci- Bank Marketing, DNN, KNN, Random Forest. 


\section{i. Pendahuluan}

Promosi konvensional produk bank biasanya melalui brosur dan kunjungan karyawan ke nasabah secara langsung. Namun, ini kurang efektif karena eksposur yang terbatas kepada klien potensial. Jadi, strategi telemarketing adalah salah satu cara untuk meningkatkan eksposur produk kepada calon klien. Strategi ini sangat membantu para pemasar dan pelaku usaha untuk memperkenalkan produk dan jasanya kepada masyarakat luas dalam waktu yang singkat [1]. Selain itu, produk yang ditawarkan melalui telemarketing cenderung mudah diterima, karena ditujukan langsung kepada konsumen.

Saat ini, metode telemarketing biasanya dilakukan oleh beberapa perusahaan operator besar untuk menawarkan produknya kepada apa yang mereka anggap sebagai calon klien. Salah satu faktor keberhasilan telemarketing adalah jika produk tersebut dibutuhkan oleh pelanggan. Namun, seringkali sulit untuk mengidentifikasinya. Selain itu, kesuksesan telemarketing seringkali sulit untuk diketahui atau diukur. Dengan mengetahui sukses tidaknya sebuah telemarketing, kita bisa mengidentifikasi pola untuk menemukan calon klien untuk masa depan. Oleh karena itu, ini dapat digunakan untuk merancang strategi telemarketing [4]. Penambangan data dan pembelajaran mesin dapat digunakan untuk tujuan yang disebutkan di atas [2].

Pada studi sebelumnya oleh [2], algoritma Naïve Bayes, Decision Tree, dan Neural Network digunakan untuk dataset Bank Marketing. Hasil penelitian menunjukkan bahwa pengklasifikasi Decision Tree berkinerja lebih baik daripada pengklasifikasi Naïve Bayes dan Neural Network. Dalam [3], Logistic Regression, Decission Tree, Naïve Bayes dan Random diimplementasikan untuk tujuan yang sama. Random Forest Esemble menjadi yang terbaik saat data pertama kali diseimbangkan. Studi ini juga menemukan algoritma Decision Tree (CART) ternyata memiliki kinerja yang lebih baik daripada algoritma Logistic Regression (LR) dan Naïve Bayes (NB).

Meskipun metode konvensional dapat mencapai akurasi untuk prediksi keberhasilan dan kegagalan pemasaran jarak jauh, masih dapat ditingkatkan. Salah satu metode potensial adalah DNN. Ini karena, relasi nonlinier antar fitur data dapat dimodelkan dengan lebih baik menggunakan DNN daripada metode 
konvensional lainnya. Di sini, kami mengusulkan arsitektur DNN untuk tugas ini dengan memvariasikan jumlah lapisan tersembunyi DNN. Memiliki lebih banyak hidden layers memungkinkan DNN untuk membuat model hubungan nonlinier dengan lebih baik. Namun, kekurangannya adalah waktu komputasi dan data yang lengkap. Eksperimen kami menunjukkan bahwa DNN dengan 3 lapisan tersembunyi lebih baik daripada metode pembelajaran mesin konvensional yang dievaluasi.

\section{Metode Penelitian}

Pembelajaran mesin adalah metode analisis data dan merupakan bagian dari kecerdasan buatan yang didasarkan pada kemampuan untuk mempelajari data yang sudah ada sebelumnya, mengenali pola dan distribusi data serta digunakan untuk membuat keputusan. Sistem ini membangun model analitik otomatis yang meminimalkan campur tangan manusia.

\section{a. Deposito}

Deposito berjangka adalah jenis simpanan yang diterbitkan oleh bank, berbeda dengan rekening giro dan tabungan dimana simpanan berjangka mengandung unsur yang memiliki masa jatuh tempo yang lebih panjang (maturity) dan tidak dapat ditarik setiap saat. Bank sepenuhnya didanai oleh simpanan, persaingan bank yang ketat akan meningkatkan dana bank dengan menaikkan suku bunga simpanan, suku bunga simpanan sebagai ukuran intensitas simpanan dalam persaingan pasar. Dalam hal ini, bank dapat memanfaatkan para deposan dengan menginvestasikan kekayaan asetnya di perusahaan [4].

\section{b. Deep Learning}

Deep Learning adalah teknik dalam pembelajaran mesin yang memanfaatkan banyak lapisan pemrosesan informasi nonlinier untuk melakukan ekstraksi fitur, pemrosesan pola, dan klasifikasi. Deep Learning merupakan salah satu bagian dari Machine Learning yang memanfaatkan teknik Neural Network atau jaringan syaraf tiruan dalam menyelesaikan suatu masalah [5].

Deep Learning pada dasarnya adalah area baru dalam pembelajaran mesin. Metode ini dilatarbelakangi oleh penelitian kecerdasan buatan yang bertujuan untuk meniru kemampuan manusia dalam mengamati, menganalisis, mempelajari dan mengambil keputusan, terutama untuk memecahkan masalah yang sulit dan kompleks. Pada prinsipnya metode DL dapat dikatakan sebagai salah satu penelitian di bidang pemrosesan sinyal, jaringan saraf tiruan, pemodelan grafis, 
optimasi dan pengenalan pola. Reputasi penelitian saat ini di DL didorong oleh peningkatan yang signifikan dalam kekuatan pemrosesan chip komputer, penurunan drastis harga perangkat keras, dan penelitian lanjutan di bidang pembelajaran mesin [6].

\section{c. Deep Neural Network (DNN)}

Algoritma DNN (Deep Neural Networks) merupakan algoritma berbasis neural network yang dapat digunakan untuk pengambilan keputusan. Deep Neural Networks mempunyai tujuan meniru cara kerja otak manusia dengan metode Multi Layer. DNN ini terdiri dari beberapa Lapisan Tersembunyi dengan koneksi antar lapisan tetapi tidak ada koneksi antar unit di setiap lapisan. Pendekatan ini memungkinkan data yang kompleks untuk dimodelkan dengan lebih mudah. Metode ini memiliki arsitektur yang mirip dengan Jaringan Syaraf Tiruan (JST), dengan Pelatihan yang Diawasi. Dengan mengidentifikasi masukan dan mencocokkannya dengan pola yang sulit [7].

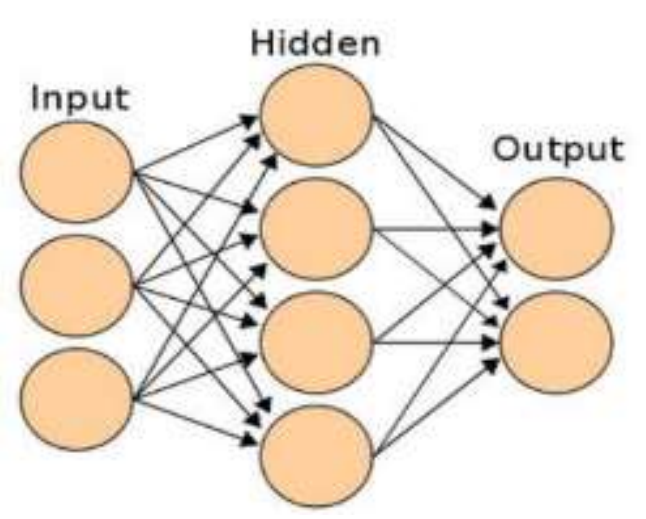

Gambar 1. DNN Layer

Deep Neural Network (DNN) adalah tiruan dengan jumlah hidden layers yang lebih besar antara lapisan masukan dan keluaran. Pada studi ini dibuat deep neural network (DNN) dengan multi layer yang saling berhubungan antara input dan output layer, dimana setiap hidden layer memiliki 3 variasi. Arsitektur DNN yang diusulkan menggunakan 2, Encoder dan decoder, variasi Learning 3 dan variasi Optimizer 3 dalam algoritma klasifikasi yang mendasarinya [8].

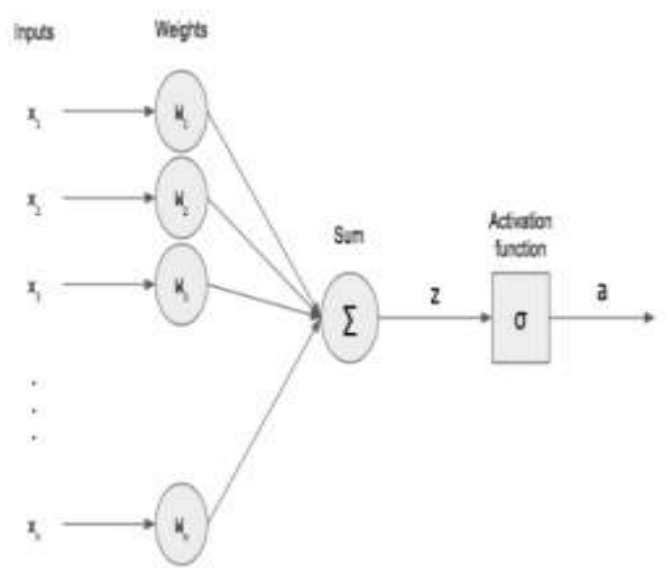

Gambar 2. Single Perceptron

Pada Gambar 1, menggambarkan bahwa setiap neuron atau satu perceptron 
menerima masukan dari lapisan masukan (xi-n). Setiap fitur x memiliki bobotnya sendiri (w). Kemudian untuk setiap neuron, lakukan operasi linier dengan menjumlahkan jumlah bobot semua input $\Sigma$ (wnxn) dan menambahkan bias (b). Hasil (z) akan dioperasikan dengan fungsi aktivasi $(\sigma)$.

Jadi secara formal dapat didefinisikan dengan persamaan (1):

$$
y_{i}=\sigma\left\{\sum_{i=0}^{n} w^{i} x^{i}+b\right\}
$$

Fungsi aktivasi mengoperasikan hasil pembobotan input dan bias untuk menentukan apakah suatu neuron diaktifkan atau tidak. Dengan memanipulasi data melalui proses penurunan gradien yang menghasilkan keluaran untuk jaringan saraf [13] .

Fungsi aktivasi sigmoid dikaitkan dengan fungsi logistik atau non-linier yang biasa digunakan di FFNN. Fungsi sigmoid pada persamaan (2) menghasilkan nilai mendekati 0 dan 1. Sigmoid diterapkan pada lapisan keluaran.

$$
\sigma=\frac{1}{\left(1+\exp ^{-z}\right)}
$$

Fungsi aktivasi Rectified Linear Unit (ReLU) menghasilkan operasi batas pada setiap elemen masukan di mana nilai yang kurang dari nol akan menjadi nol, lebih dari nol sebagai fungsi linier. Fungsi ULT dengan persamaan (3) diterapkan ke lapisan tersembunyi di DNN [14] .

$$
\sigma=\max (0, z)=\left\{\begin{array}{l}
z_{\mathrm{i}}, \text { if } z_{\mathrm{i}} \geq 0 \\
z_{s} \text { if } \mathrm{z}_{\mathrm{i}}<0
\end{array}\right.
$$

d. Arsitektur

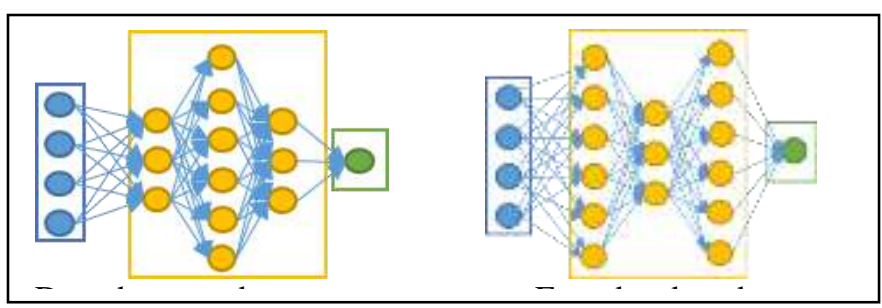

Gambar 3. Arsitektur Deep Learning Neural Network

Ada beberapa jenis arsitektur jaringan saraf, termasuk jaringan feedforward, jaringan berulang, dan jaringan fungsi basis radial. Model feed forward neural network (FFNN) merupakan model yang sering digunakan untuk tujuan prediksi [12].

\section{e. Random Forest}

Metode Ensembel Random Foorest dalam hal pembelajaran digunakan untuk klasifikasi, regresi, dan tugas lainnya. Random Forest acak pertama kali diusulkan oleh Tin Kam Ho dan dikembangkan lebih lanjut oleh Leo Breiman dan Adele Cutler. Performa Random Forest acak diadaptasi dari 
Decission Tree, dengan setiap pohon dikembangkan dari sampel bootstrap berdasarkan data pelatihan. Saat mengembangkan pohon, subset atribut diambil secara acak dari atribut terbaik yang akan dipilih untuk dipisahkan. Model akhir dari Random Forest acak didasarkan pada hasil dari seluruh subset pohon yang telah dikembangkan [9].

Random Forest adalah metode pembelajaran melalui pembangunan Decission Tree melalui pelatihan. Ada tiga aspek penting dalam metode random forest, yaitu:

1. Lakukan pengambilan sampel bootstrap untuk membuat Decission Tree.

2. Setiap Decission Tree diprediksi dengan prediktor acak.

3. Kemudian Random Forest acak membuat prediksi dengan menggabungkan hasil dari setiap Decission Tree dengan cara suara terbanyak untuk klasifikasi atau ratarata untuk regresi [10].

\section{f. K-nearest neighbor}

Algoritma K-nearest neighbor (k-NN atau KNN) merupakan metode untuk mengklasifikasikan objek berdasarkan data pembelajaran yang paling dekat dengan objek, akurasi algoritma k-NN sangat dipengaruhi oleh ada tidaknya fitur yang tidak relevan., atau jika bobot fitur tidak setara dengan relevansinya dengan klasifikasi [11]. Dalam mengklasifikasikan algoritma K-NN dengan cara mencocokkan bobot dan fitur yang terdapat pada dataset. Penggunaan $\mathrm{K}$ dalam algoritma K-NN digunakan untuk menentukan jumlah tetangga yang ada dan digunakan untuk mengambil keputusan [12]. Sebagian besar penelitian tentang algoritma ini membahas tentang bagaimana memilih dan memberi bobot pada fitur, agar performansi klasifikasi lebih baik, KNN juga merupakan contoh dari teknik lazy learning yaitu teknik menunggu query datang sama. sebagai data pelatihan. [11].

\section{Hasil dan Pembahasan}

Dalam penelitian ini, data yang digunakan adalah Kumpulan Data Pemasaran Bank yang diperoleh dari data publik yaitu UCI Machine Learning Repository dengan link: https://archive.ics.uci.edu/ml/datasets/Ban $\mathrm{k}+$ Marketing.

Dalam penelitian ini akan dilakukan beberapa tahapan atau tahapan penelitian, seperti dibawah ini: 


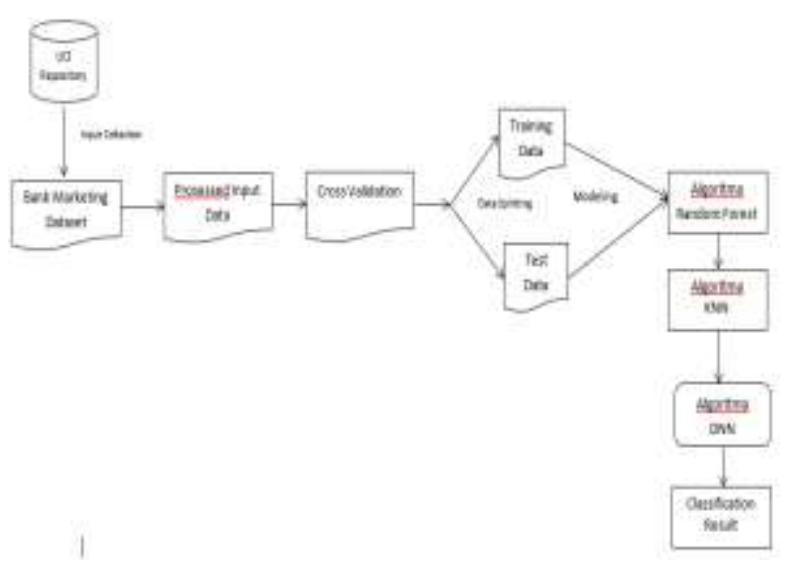

\section{Gambar 4. Tahapan Penelitian}

Teknik pengumpulan data yang digunakan oleh penulis adalah dengan pendekatan kualitatif dimana teknik yang digunakan penulis adalah survei literatur akademis pada bidang keilmuan atau kebijakan guna mendapatkan konsepkonsep yang relevan dengan kajian inovasi kebijakan dari masyarakat [13] . Dalam pengumpulan data terdapat 2 (dua) sumber data yaitu sekunder dan primer, data primer diperoleh informasi kunci / informan sedangkan data sekunder diperoleh dari hasil analisis penulis terhadap informasi kunci dan jawaban informan yang telah ditautkan. ke tabel pengkodean dan teori strategis PR. (dokumen dan data jurnal, buku ilmiah dan internet) [14].

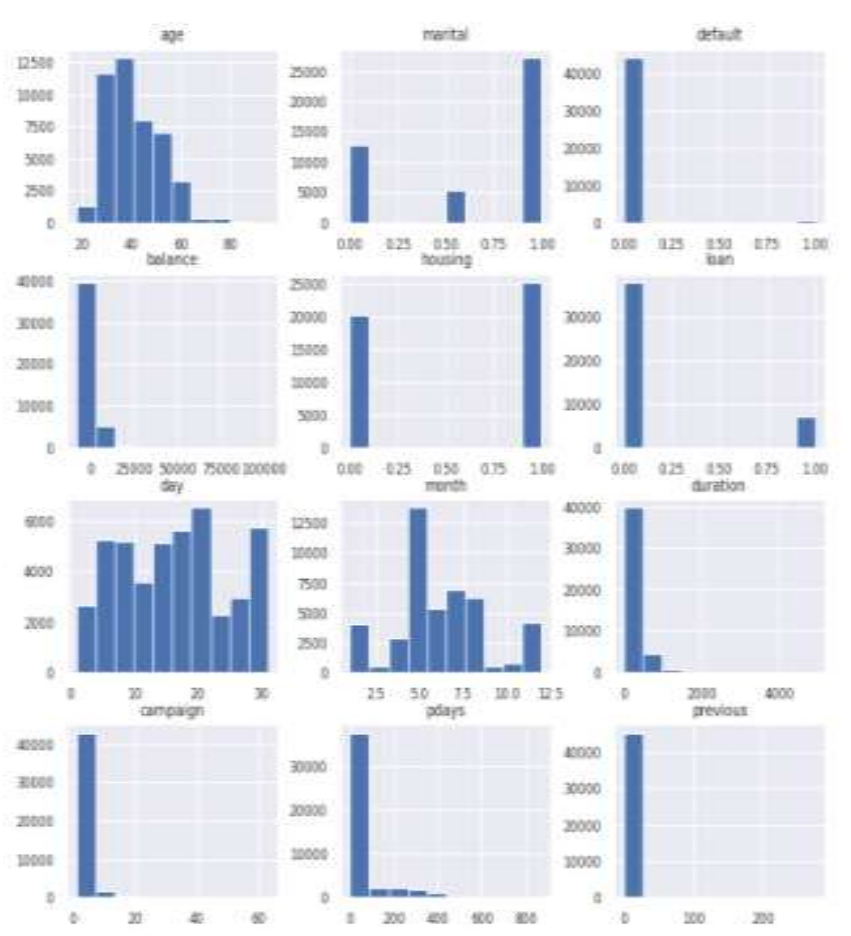

\section{Gambar 5. Histogram Dataset}

Kemudian jika dilihat tingkatan dari data kampanye dalam satu tahun dapat dilihat pada grafik pada Gambar 3 berikut ini.

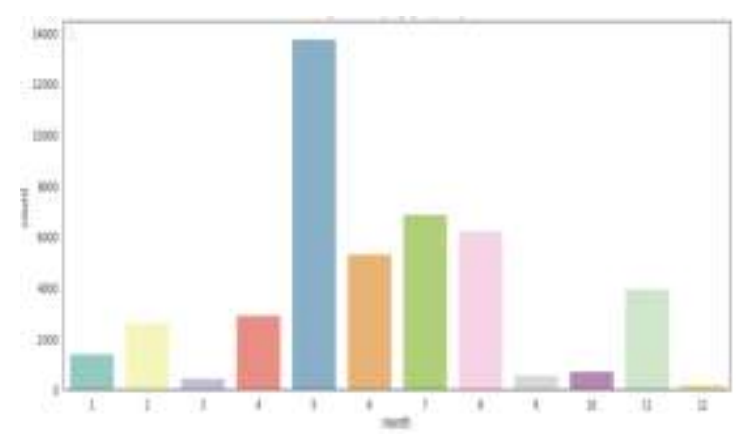

Gambar 6. Grafik Jumlah Kampanye per bulan dalam 1 tahun.

Pada tahap ini peneliti melakukan percobaan dan pengujian dengan beberapa metode yaitu Klasifikasi yang meliputi Deep Neural Network (DNN) dengan 2 
Hidden Layers, Deep Neural Network (DNN) dengan 3 Hidden Layers, Deep Neural Network (DNN) dengan 4 Hidden Layers, Random Forest, K-nearest neighbour (K-nn). Penulis menambahkan teknik data mining berupa Cross Validation yang bertujuan untuk mendapatkan hasil akurasi yang maksimal. Cara ini sering juga disebut k-fold cross validation, dimana percobaannya dilakukan k kali untuk satu model dengan parameter yang sama.

Tabel 2. Eksperimen Multi Layer Percepton (MLP) pada DNN dengan 3 Hidden layers

\begin{tabular}{|c|c|c|c|c|c|c|c|c|}
\hline Arsitecture & Activation & Optimizer & Layer (type) & $\begin{array}{l}\text { Output } \\
\text { Shape }\end{array}$ & Param & $\begin{array}{l}\text { Total } \\
\text { Params }\end{array}$ & $\begin{array}{l}\text { Trainable } \\
\text { Params }\end{array}$ & $\begin{array}{l}\text { Non- } \\
\text { trainable } \\
\text { params }\end{array}$ \\
\hline \multirow{10}{*}{$\begin{array}{l}\text { Decoder- } \\
\text { Encoder }\end{array}$} & \multirow{20}{*}{$\begin{array}{l}\text { Relu, } \\
\text { Sigmoid }\end{array}$} & \multirow{20}{*}{ Adam } & $\begin{array}{l}\text { Batch_normalization_60 } \\
\text { (batc) }\end{array}$ & (None, 12$)$ & 48 & \multirow{10}{*}{12.199} & \multirow{10}{*}{11.875} & \multirow{10}{*}{324} \\
\hline & & & Dense_80 & $\begin{array}{l}\text { (None, } \\
100)\end{array}$ & 1300 & & & \\
\hline & & & $\begin{array}{l}\text { batch_normalization_61 } \\
\text { (batc) }\end{array}$ & $\begin{array}{l}\text { (None, } \\
100)\end{array}$ & 400 & & & \\
\hline & & & Dropout_60 (dropout) & $\begin{array}{l}\text { (None, } \\
100)\end{array}$ & 0 & & & \\
\hline & & & dense_81 (dense) & (None, 50) & 5050 & & & \\
\hline & & & $\begin{array}{l}\text { batch_normalization_62 } \\
\text { (batc) }\end{array}$ & (None, 50) & 200 & & & \\
\hline & & & Dropout_61 (dropout) & (None, 50) & 0 & & & \\
\hline & & & dense_82 (dense) & $\begin{array}{l}\text { (None, } \\
100)\end{array}$ & 5100 & & & \\
\hline & & & Dropout_62 (dropout) & $\begin{array}{l}\text { (None, } \\
100)\end{array}$ & 0 & & & \\
\hline & & & dense_83 (dense) & (None, 1$)$ & 101 & & & \\
\hline \multirow{10}{*}{$\begin{array}{l}\text { Encoder- } \\
\text { Decoder }\end{array}$} & & & $\begin{array}{l}\text { Batch_normalization_60 } \\
\text { (batc) }\end{array}$ & (None, 12) & 48 & \multirow{10}{*}{11.499} & \multirow{10}{*}{11.175} & \multirow{10}{*}{324} \\
\hline & & & Dense_80 & (None, 50) & 650 & & & \\
\hline & & & $\begin{array}{l}\text { batch_normalization_61 } \\
\text { (batc) }\end{array}$ & (None, 50) & 200 & & & \\
\hline & & & Dropout_60 (dropout) & (None, 50) & 0 & & & \\
\hline & & & dense_81 (dense) & $\begin{array}{l}\text { (None, } \\
100)\end{array}$ & 5100 & & & \\
\hline & & & $\begin{array}{l}\text { batch_normalization_62 } \\
\text { (batc) }\end{array}$ & $\begin{array}{l}\text { (None, } \\
100)\end{array}$ & 400 & & & \\
\hline & & & Dropout_61 (dropout) & $\begin{array}{l}\text { (None, } \\
100)\end{array}$ & 0 & & & \\
\hline & & & dense_82(dense) & (None, 50) & 5050 & & & \\
\hline & & & Dropout_62 (dropout) & (None, 50) & 0 & & & \\
\hline & & & dense_83 (dense) & (None, 1$)$ & 51 & & & \\
\hline
\end{tabular}


Hasil pengujian prediksi tingkat kesuksesan promosai bank menggunakan 20;80 data testing dan data training. Dengan menggunakan arsitektur yang baik berdasarkan hasil pengujian, yaitu 3 hidden layer,learning rate dan dilakukan percobaan testing 10 epoch di dapat nilai akurasi terbaik sebesar 90\% pada epoch ke-10. Hasil percobaan testing untuk mendapatkan akurasiterbaik ditunjukkn pada table 2 .

Tabel 2. Hasil pengujian 10 epoch pada DNN dengan 3 Hidden layers

\begin{tabular}{|l|l|l|l|l|l|}
\hline Epoch & $\operatorname{Lr}(\alpha)$ & $\operatorname{loss}$ & Binary_acc & vall_loss & acc \\
\hline 1 & 0,1 & 0.2537 & 0.8899 & 0.2515 & 0.8882 \\
\hline 2 & 0,1 & 0.2535 & 0.8909 & 0.2521 & 0.8880 \\
\hline 3 & 0,1 & 0.2516 & 0.8901 & 0.2496 & 0.8910 \\
\hline 4 & 0,1 & 0.2502 & 0.8915 & 0.2511 & 0.8884 \\
\hline 5 & 0,1 & 0.2496 & 0.8907 & 0.2542 & 0.8883 \\
\hline 6 & 0,1 & 0.2501 & 0.8910 & 0.2520 & 0.8882 \\
\hline 7 & 0,1 & 0.2499 & 0.8915 & 0.2527 & 0.8901 \\
\hline 8 & 0,1 & 0.2503 & 0.8915 & 0.2522 & 0.8914 \\
\hline 9 & 0,1 & 0.2499 & 0.8923 & 0.2530 & 0.8896 \\
\hline 10 & 0,1 & 0.2475 & 0.8927 & 0.2498 & 0.9005 \\
\hline
\end{tabular}

Tabel 3. Perbandingan Nilai Akurasi Algoritma Klasifikasi

\begin{tabular}{|l|l|}
\hline Algoritma & Hasil Akurasi \\
\hline DNN - 2 Hidden Layers & $89 \%$ \\
\hline DNN - 3 Hiden Layers & $90 \%$ \\
\hline DNN - 4 Hidden Layers & $89 \%$ \\
\hline Random Forest & $88 \%$ \\
\hline KNN & $89 \%$ \\
\hline
\end{tabular}

\section{Simpulan}

Dari hasil penelitian yang telah dilakukan algoritma Deep Neural Network (DNN) dengan 3 Hidden Layers memiliki nilai akurasi yang lebih tinggi dibandingkan dengan menggunakan algoritma K-Nearest Network (KNN) dan algoritma Random Forest. Nilai akurasi untuk model algoritma Deep Neural Network (DNN) dengan 3 Hidden Layers sebesar 90\% sedangkan nilai akurasi untuk Deep Neural Network (DNN) dengan 2 Hidden Layers sebesar 89\%, Deep Neural Network (DNN) dengan 4 Hidden Layers sebesar 89\%, algoritma K-Nearest Network (KNN) sebesar 89\% dan algoritma Random Forest sebesar 88\%. Sehingga dapat disimpulkan bahwa penerapan algoritma Deep Neural Network (DNN) dengan 3 Hidden Layers mampu menghasilkan tingkat akurasi dalam memprediksi tingkat kesuksesan promosi bank yang lebih baik dibandingkan menggunakan algoritma yaitu algoritma KNearest Network (KNN) dan algoritma Random Forest.

\section{DAFTAR PUSTAKA}

[1] E. P. Saputra, "Prediksi Keberhasilan Telemarketing Bank Untuk," J. Ilmu Pengetah. Dan Teknol. Komput., vol. 2, no. 2, pp. 66-72, 2017.

[2] G. F. Yee, S. F. Sufahani, M. Mamat, M. A. Mohamed, and P. L. Ghazali, "Analog the performance between three classifiers on bank marketing data," Int. J. Recent Technol. Eng., 
vol. 8, no. 2 Special Issue 3, pp. 382386 ,

2019 ,

doi:

10.35940/ijrte.B1066.0782S319.

[3] O. Apampa, "Evaluation of Classification and Ensemble Algorithms for Bank Customer Marketing Response Prediction.," $J$. Int. Technol. Inf. Manag., vol. 25, no. 4, pp. 85-100, 2016.

[4] R. Sulaehani, "Prediksi Keputusan Klien Telemarketing Untuk Deposito Pada Bank Menggunakan Algoritma Naive Bayes Berbasis Backward Elimination," Ilk. J. Ilm., vol. 8, no. 3, pp. 182-189, 2016, doi: 10.33096/ilkom.v8i3.83.182-189.

[5] P. A. Wicaksana, I. M. Sudarma, and D. C. Khrisne, "Pengenalan Pola Motif Kain Tenun Gringsing Menggunakan Metode Convolutional Neural Network Dengan Model Arsitektur," J. SPEKTRUM, vol. 6, no. 3, pp. 159-168, 2019.

[6] L. M. R. Rere and S. Sudjiran, “Optimasi Deep Belief Network MenggunakanSimulated Annealing," vol. 2, 2018.

[7] A. Anggoro, A. B. Osmond, and R.

E. Saputra, "Recurrent Neural Network Untuk Pengenalan Ucapan Pada Recurrent Neural Network for Speech Recognition on," vol. 5, no. 3, pp. 6431-6435, 2018.

T. L. Fine, "Feedforward Neural Network Methodology," IEEE Trans. Neural Networks, vol. 12, no. 3, pp. 647-648, 2001, doi: 10.1109/TNN.2001.925573.

[9] I. Oktanisa and A. A. Supianto, "Perbandingan Teknik Klasifikasi Dalam Data Mining Untuk Bank a Comparison of Classification Techniques in Data Mining for," Teknol. Inf. dan Ilmu Komput., vol. 5, no. 5, pp. 567-576, 2018, doi: 10.25126/jtiik20185958.

[10] R. Leonardo, J. Pratama, and C. Chrisnatalis, "Perbandingan Metode Random Forest Dan Naïve Bayes Dalam Prediksi Keberhasilan Klien Telemarketing," J. Teknol. Dan Ilmu Komput. Prima, vol. 3, no. 2, pp. 1-5, 2020 .

[11] S. Dewi, "Pada Prediksi Keberhasilan Pemasaran Produk Layanan Perbankan," Techno Nusa Mandiri, vol. XIII, no. 1, pp. 60-66, 2016.

[12] W. Darmawan, "Komparasi Metode Data Mining Dalam Memprediksi Nasabah Bank yang akan Memilih Tabungan Deposito Menggunakan Algoritma Klasifikasi," IC-Tech, vol. XIII, no. 1, pp. 49-55, 2018.

[13] A. Sururi, "Inovasi Kebijakan dalam 
Perspektif Administrasi Publik

Menuju Terwujudnya Good Public

Policy Governance," vol. 12, pp. 14-

31, 2017, doi: 10.31227/osf.io/6djph.

[14] R. Rosliana and R. Loisa, "Strategi

Cyber Public Relatons dalam

Memanfaatkan Media Sosial untuk

Membangun Citra Perusahaan,"

Prologia, vol. 2, no. 2, p. 480, 2019, doi: 10.24912/pr.v2i2.3733.

[15] Wibowo, H., \& Indriyani, F. (2018, October). K-Nearest Neighbor Method For Monitoring Of Production And Preservation Information (Treatment) Of Rubber Tree Plant. In International Conference on Information Technology and Business (ICITB) (pp. 29-44). 